\title{
小学英语课堂教学模式的构建
}

\author{
王丹 \\ 鄂尔多斯市康巴什区第二小学 \\ DOI:10.32629/jief.v2i10.2322
}

[摘 要] 新课程标准倡导 “在做中学”理念, 注重英语教学的工具性, 为了更适应新的教学目标, 我们在互动式教学模式的构建上做了新的 探索，互动式教学能激发学生的学习兴趣、提升课堂的学习效率，因此，可以在课堂上增加师生间的提问环节、创设生活情境来让学生表演、 教师对学生的表现给予即时鼓励等, 通过这些方式来构建课堂互动性。

[关键词] 小学; 英语; 课堂教学; 互动模式

中图分类号: G623 文献标识码: A

\section{1 小学英语课堂互动式教学的重要性}

新课程标准中提出要注重英语教学的工具性, 倡导 “在做中学”, 为 了加强对学生英语运用能力的提升, 在课堂上应该增加师生互动以及学 生之间互动的环节, 让学生们英语表达能力的提升在课堂上能够展现出 来。并且互动式的教学课堂, 有利于吸引学生的注意力, 激发小学生的 学习兴趣, 学生对于知识的理解情况老师能够及时了解, 并给予正确的 引导, 互动式的教学课堂提升了课堂学习效率, 有利于构建师生有效的 学习交流氛围。

\section{2 小学英语课堂互动式教学现状}

2.1 小学英语教学采用幼儿式互动教学

在日常课堂教学中, 一些教师也非常重视活跃课堂的范围, 采用做 游戏等手段达到吸引学生注意力、让学生们都参与到课堂的目的, 但是 采用的形式太过于简单, 比如课堂上抛球、手工制作, 和幼儿英语教学 中的活动教学法非常类似, 这样只能让同学们记住一些单词和句型, 并 没有真正提升语言学习能力。在小学英语课堂上仅仅达到这样的目的, 是对小学生智力和逻辑思维能力发展的忽视, 也是对小学培养和发展儿 童语言能力黄金阶段的一种浪费。

\section{2 小学英语互动式教学中学化}

有些教师则没有注意到小学生的知识水平仍处于启蒙阶段, 也忽视 了他们的思维特点, 教学采用初中化的课本教学方法, 逐词逐句的为同 学们翻译文章和讲解语法。首先, 以幼儿的智力发展, 他们肯定不能完 全掌握住所教授的语法知识, 另外, 小学阶段的英语教学主要是为了让 学生去积累各种语言素材, 自主构建一定的英语知识网, 而在没有语言 积累的情况下早早去枯燥的讲解语法知识, 这样的课堂虽然也有互动, 教师会提问同学许多知识点, 同学们在底下认真思考怎么来翻译这一段 长句, 但是往往大多数的学生会回答不上来, 反而抑制了学生学习英语 的兴趣和信心。

\section{3 适应小学英语互动式课堂的几点建议}

3.1 进行有效的课堂提问，促进师生间的思想交流活动

在孩子成长过程中, 有一 “脚手架” 理论, 即在儿童成长过程中, 其与成人间的良好互动或者与同龄中优秀的孩子的良好交往, 会像脚手 架一样, 极大地帮助儿童快速构建自我成长的大厦。因此, 教师要非常 重视自己与学生们的良好交流与互动, 课堂提问是互动式教学的一个方 法, 其能帮助教师更多地了解儿童内心所思所想, 增加师生间的良好交 流互动, 提升了小学课堂教学的活跃气氛, 这不仅能鼓励儿童积极主动 构建英语知识网, 也能帮助他们树立良好的交流習惯和自信心。比如, 在学习小学英语六年级下册 Unit9Where will you go? 这堂课, 这节课 讲的是有关假日旅游的内容, 和小学生的生活也息息相关, 课堂之前不 妨预先准备多些问题, 让同学们大胆交流自己的生活, 我在课堂上就准 备提问学生这些问题：(1)Where have you gone on holiday? What activities do you do here? (2)How many excellent places do you now? What are they like? (3)Which is your favorite place? Why do you like it? 这一堂课下来, 基本每位学生都有发言的机会, 我们将收获更多有 关旅游景点的内容。

3.2 角色扮演走进课堂, 增加学生的互动机会

课堂上也可以成为一个舞台, 让学生拥有实际演练的机会, 如今, 角色扮演活动已经悄无声息地加入到小学课堂中, 通过角色扮演可以自 由组织各种情景对话, 促进学生之间的交流, 不仅能更好地帮助学生记 忆课堂知识, 还锻炼了学生的语言运用表达能力, 并且小学生自身的特 点就是好动、热爱表演, 这样可以激发学生学习英语的兴趣, 增进师生 间的交流, 创造良好的学习氛围。比如在学习广州版小学五年级上册中 的 Do you want coffee or tea? 单元时, 在学习完 “tea, milk, juice, water, coke, bread” 等单词, 以及基本句型 “What do you want to drink for... ? I will / want to have a cup of tea”之后, 我会把教室预 先简单布置成一个饮品店, 课堂上让同学们来扮演售货员和顾客, 扮演 售货员的同学会说 “Can I help you? Do you want coffee or tea? ” 等话语，然后扮演顾客的同学会像售货员说: “We11, I wan something hot.Cause I feel cold. Can I have a cup of hot tea, please?”, 通过角色扮演将语言的情景展现出来, 让同学们能够更设身处地地来进 行交流, 强化学生的语言运用能力。

3.3 对学生的互动活动给予积极评价

如果想让学生对课堂互动性始终充满兴趣, 教师就必须对学生在课 堂上的互动表现和成果即时给予正面评价, 使同学们知道自己思考总结 的内容, 老师已经认真聆听了, 让学生们感受到老师的认可、享受到被 表扬的喜悦。这样他们会更加积极地思考, 更勇于和老师交流, 创造出 一种活跃、热情的课堂氛围。比如, 在学生回答完问题后, 教师可以给 一个他小小的肯定的话语, “Good!” “Excellent!” “correct!” “Very good!” 等, 学生在课堂上的劳动成果需要得到老师的认可, 让学生感觉 自己的思考有意义, 从而真正热爱上学习英语, 以后更加积极主动地去 加入到自己感兴趣的课程中去。

互动式课堂能帮助激发学生学习英语的兴趣, 积极参加到课程中去; 同时互动式课堂又可以提高课堂效率, 达到了良好的学习效果, 是一种 适应小学课堂教育的优秀的教学方式。

[参考文献]

[1]周秋笉.奏响小学高段英语语篇阅读教学三步曲[J].英语广场 ( 学 术研究）.2015(1):167-168.

[2]黄㑆.小学中高年级英语绘本教学的思路及建议——绘本 Just Be Yourselves 的教学为例 [J]. 江苏教育.2018(81):67-68.70.

[3]孙瑶.浅谈现代小学英语阅读教学模式的创新 [J].教育现代 化.2017.4(50):379-380. 